\title{
First Data on Nosocomial Myiasis caused by Wohlfahrtia magnifica in Tunisia
}

Cheikhrouhou Fatma, Talbi Roua, Triki Zied, Karoui Abdelhamid, Makni Fattouma and Ayadi Ali*

Laboratory of Parasitology and Mycology, University Hospital of Habib Bourguiba, University of Sfax, Tunisia

*Corresponding author: Ayadi Ali, Laboratory of Parasitology and Mycology, University Hospital of Habib Bourguiba, University of Sfax, Tunisia, Tel/Fax: 0021674247130; E-mail: ali.ayadi@rns.tn

Rec date: Jun 24, 2015, Acc date: Jul 24, 2015, Pub date: Jul 26, 2015

Copyright: (C) 2015 Fatma C, et al. This is an open-access article distributed under the terms of the Creative Commons Attribution License, which permits unrestricted use, distribution, and reproduction in any medium, provided the original author and source are credited.

\section{Abstract}

Myiasis is the infestation of live human and vertebrate with dipterous larvae that feed on the host's tissues. We report a case of a nosocomial oral myiasis in an unconscious patient.

Keywords: Myasis; Wohlfahrtia magnifica; Tunisia

\section{Introduction}

The term myiasis (Greek: myi $=$ fly, asis $=$ disease) is used to refer to the infestation of living tissues of human and animals by dipterous larvae [1]. It occurs worldwide, but more often in hot and humid climates. Each fly species has specific geographical distribution. Species causing myiasis can be obligate, facultative, or accidental.

Clinical presentation of myiasis varies according to the causatives species involved and the anatomical location of the larvae [2].

Although myiasis is a common phenomenon to be observed in skin in people and animals living in tropical and subtropical areas, it has rarely affected the oral cavity $[3,4]$.

It is important to draw attention to the hazard of myiasis under exceptional conditions. Nosocomial myiasis, first reported in 1980, is a term used when the infestation affects subjects in hospital settings. Unfortunately, it happens particularly in patients with open wounds/ sores and areas that are heavely infested with flies.

Sadly, care taker neglect may be a factor in such places as nursing homes or hospices. Here, we report a very rare case of infection in a patient admitted to an urology unit in Sfax, (South of Tunisia).

\section{Case Report}

An 85 year-old man was transferred from regional hospital of Jbeniana Sfax on the $13^{\text {th }}$ October 2014 , to the urology unit for cystoscopy in order to insert a urethral probe. The patient having a unique left kidney, suffered from pyelonephritis and presented a uremic syndrome thus has had a hemodialysis session.

In the urology unit, due to the worsening of the renal function, the patient has few more hemodialysis sessions. The intervention took place on the $30^{\text {th }}$ October 2014 and lead in a circulatory shock. Therefore, the patient was transferred to the surgical intensive care unit (SICU). An intubation was performed, a nasogastric feeding tube was placed, appropriate therapy initiated and the patient was kept sedated.

On the first day of hospitalization, while performing an oropharyngeal aspiration, about 20 maggots were found fortuitously. Maggots were seen on the palate and around the intubation pipe. The maggots were, then, sent to the parasitology laboratory for identification. The patient dead after two days due to a circulatory shock. The larvae showed the typical maggot like body shape and were identified as the third instar of Wohlfahrtia magnifica. Identification of larvae by light microscopy was carried out by examination of their size, segmentation, posterior spiracles, cephalo-pharngeal skeleton and spines.

Before being mounted on slides, the larvae were cleared in a $30 \%$ aqueous solution of $\mathrm{KOH}$. Additional maggots were conserved in formol. Species identification was done using the following keys:

- Pictorial keys to arthropods, reptiles, birds and mammals of public health significance.

- Keys for identification of immature insects.

- Laboratory identification of arthropod ectoparasites.

The collected maggots were $10-18 \mathrm{~mm}$ in length with a beige coloring (Figure 1).

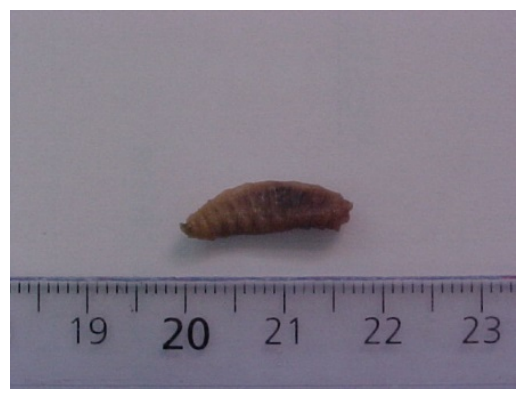

Figure 1: The larva of Wohlfahrtia magnifica.

The peritermal cavity appears as a deep depression. It included the posterior spiracles. The spiracle area was surrounded by 10 to more tubercules symmetrically arranged. The larvae also showed an incomplete peritreme.

The inner slit within the spiracles were directed away from the median line ventrally (Figures 2 and 3). The larvae had as well two thick and long curved hooks (Figure 4), anterior spiracles and spines of third instar larva. 


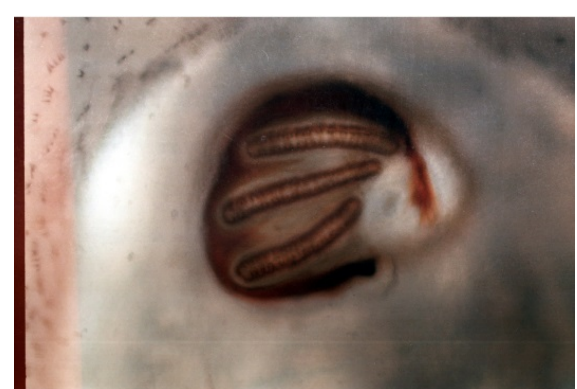

Figure 2: Light microscopic appearance of the posterior spiracules of third instar larva of Wohlfahrtia magnifica

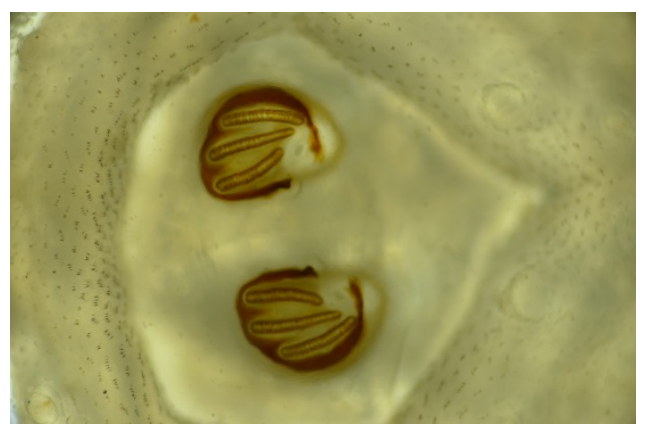

Figure 3: Light microscopic appearance of the posterior spiracules of third instar larva of Wohlfahrtia magnifica

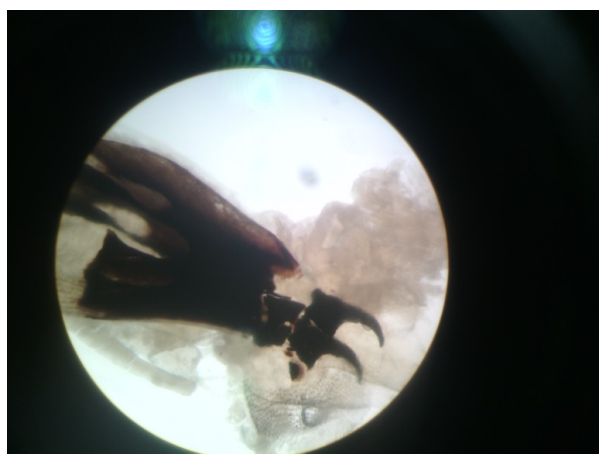

Figure 4: Cephalopharyngeal skeleton of third instar larva.

\section{Discussion}

In Tunisia, there are few reported studies on human myiasis caused by Oestrus ovis [5-9]. This is the first reported case of Wohlfahrtia magnifica myiasis in our country. The uniqueness of the present case is that myiasis occurred in a non-ambulatory patient under ventilator with naso-gastric tube and was hospital acquired. We suspected that the present case was a nosocomial infection because the patient had spent 17 days in the urology unit, and the maggots were found on the day of admission to the SICU. It is attributed to poor general hygiene in the hospital facility and reflects a lack of adequate care, especially for patients who need close attention. Flies usually attack patients who are immobile, injured or severely ill. Oral myiasis might occur in patients whose health conditions are most likely to cause prolonged mouth opening [10], which is the case for this sedated intubated patient. In a study of human myiasis in Hong Kong, the oral cavity was found to be the most affected site with myiasis in non-ambulatory patients with nasogastric feeding tube [11].

Although this form of infestation is considered rare, it may be underreported in developing poor countries. It is estimated to occur in $5 \%$ of all acute care hospitalization. Lukin and Sherman reported 5\% and $43 \%$ of nosocomial infections respectively in Australia and in North America [12,13].

The following species have been recognizes as causative agents of nosocomial species: Lucila sericata, Megaselia scalaris, Sarcophaga spp. Cochliomyia hominivorax, Cochliomyia macellaria, and Musca. domestica [2].

Wohlfahrtia magnifica is a frequent fly in countries with high breeding activity: Australia, South Africa or Arab country. The prevalence of wohlfahrtiosis in sheep and goats appears to be higher in Eastern Europe $(30 \%-50 \%)$ and lower in the Mediterranean basin countries $(0.7 \%-8.5 \%)$ [14].

Frequently, larvae of $W$. magnifica infest natural orifices [15]. The parasitological infestation occurred essentially during the summer, favorable period to the biological evolution of myiasis.

Standard guidelines for treating oral myiasis does not exist. The most followed procedure is the mechanical removal of the larvae. Some authors suggested occlusion to deprive the maggots from oxygen and make them move to the surface. The substances used are paraffin, nail polish, turpentine oil, mineral oil, ethyl chloride and petroleum $[14,16]$. Recently systemic ivermectin has been tried in many patients with successful results [17]. It is the only antibiotic which has been found to effective against maggots. Mechanism of action is through blocking nerve impulses on the nerve endings of the larvae through the release of gamma aminobutyric acid (GABA) and linking to the receptors, causing palsy and death [17].

To prevent myiasis, good personal and environmental hygiene is of paramount importance. Regular screening of the dependent's oral cavity, especially on nasogastric tube feeding, is crucial for early detection or infestation and treatment. Fly proofing measures, such as installation of window screening, insect electrocuting devices or fly trap, should be considered [15]. Prevention of nosocomial myiasis could require controlling fly populations in the hospital environment by efficient sanitary and waste disposal, reducing odours of decomposition and more radical approaches such as insecticide sprays.

Knowledge of the distribution and phenology of the species is equally important, yet data are still extremely fragmentary. More in general, accurate and comprehensive information on the distribution of species of medical and veterinary importance is lacking in Tunisia, and making 'infestation maps' available for veterinary interventions as well as for ecological and biological studies should be a priority objective.

\section{Conclusion}

Nosocomial oral myiasis is a rare and preventable disease. This paper puts emphasis on the importance of sanitation and hygiene in hospitals for the prevention of myiasis. The disease can be prevented 
Citation: Fatma C, Roua T, Zied T, Abdelhamid K, Fattouma M, et al. (2015) First Data on Nosocomial Myiasis caused by Wohlfahrtia magnifica in Tunisia. J Cytol Histol 6: 347. doi:10.4172/2157-7099.1000347

Page 3 of 3

by adequate control of insects and maintaining a good oral and corporal hygiene of the patient regardless of their consciousness state.

\section{References}

1. Navneet S, Divye M, Manjunatha BS, Jasjit K (2014) Oral Myiasis-A Case Report. Austin J Clin Case Rep 1: 1039.

2. Francesconi F, Lupi O (2012) Myiasis. Clin Microbiol Rev 25: 79-105.

3. Jang M, Ryu SM, Kwon SC, Ha JO, Kim YH, et al. (2013) A case of oral myiasis caused by Lucilia sericata (Diptera: Calliphoridae) in Korea. Korean J Parasitol 51: 119-123.

4. Jang M, Ryu S-M, Kwon S-C, Ha J-O, Kim Y-H, et al. (2013) Lucilia sericata (Diptera: Calliphoridae) in Korea. Korean J Parasitol 51: 119-123.

5. Jyothi L, Tirumal Rao T, Naveen Kumar M, Bhandari R (2013) Nosocomial Oral Myiasis- A Rare Case Report. Indian J Mednodent Allied Sci 1: 82-85.

6. Zayani A, Chaabouni M, Gouiaa R, Ben Hadj Hamida F, Fki J (1989) [Conjunctival myiasis. 23 cases in the Tunisian Sahel]. Arch Inst Pasteur Tunis 66: 289-292.

7. Ayadi A (1991) [First case of intestinal myiasis diagnosed in Sfax]. Pediatrie 46: 561.

8. Jenzeri S, Ammari W, Attia S, Zaouali S, Babba H, et al. (2009) External ophthalmomyiasis manifesting with keratouveitis. Int Ophthalmol 29: 533-535.
9. Anane S, Hssine LB (2010) [Conjonctival human myiasis by Oestrus ovis in southern Tunisia]. Bull Soc Pathol Exot 103: 299-304.

10. Kaouech E, Kallel K, Belhadj S, Chaker E (2010) [Dermatobia hominis furuncular myiasis in a man returning from Latin America: first imported case in Tunisia]. Med Trop (Mars) 70: 135-136.

11. Tam YH (2010) Review of human myiasis in Hong Kong (2002-2009). Communicable disease watch 7: 17-20.

12. Lukin LG (1989) Human cutaneous myiasis in Brisbane: a prospective study. Med J Aust 150: 237-240.

13. Sherman RA (2000) Wound myiasis in urban and suburban United States. Arch Intern Med 160: 2004-2014.

14. Ramli R, Abd Rahman R (2002) Oral myiasis : case report. Malays J Med Sci 9: 47-50.

15. Sotiraki S, Farkas R, Hall MJ (2010) Fleshflies in the flesh: epidemiology, population genetics and control of outbreaks of traumatic myiasis in the Mediterranean Basin. Vet Parasitol 174: 12-18.

16. Rajdeep S, Santosh BS, Shivmurthy DM, Savitha Ghom, Vikash M, et al. (2013) Oral myiasis in a psychological disorder patient: A case report. Chhattisgarh Journal of Health Sciences 1: 1.

17. Shinohara EH, Martini MZ, de Oliveira Neto HG, Takahashi A (2004) Oral myiasis treated with ivermectin: case report. Braz Dent J 15: 79-81. 